\title{
The Use of Integrative Leadership in Providing Excellent Patient Care While Overcoming Hospital Challenges
}

\author{
Julie D. Bolin, CNMT \\ Nuclear Medicine Technology Program, GateWay Community College, Phoenix, Arizona, and Tucson Medical Center, Tucson, \\ Arizona
}

CE credit: For CE credit, you can access the test for this article, as well as additional JNMT CE tests, online at https://www.snmmilearningcenter.org. Complete the test online no later than June 2022. Your online test will be scored immediately. You may make 3 attempts to pass the test and must answer $80 \%$ of the questions correctly to receive $1.0 \mathrm{CEH}$ (Continuing Education Hour) credit. SNMMI members will have their CEH credit added to their VOICE transcript automatically; nonmembers will be able to print out a CE certificate upon successfully completing the test. The online test is free to SNMMI members; nonmembers must pay $\$ 15.00$ by credit card when logging onto the website to take the test.

Effective leadership in the health-care setting is vital for delivering effective and efficient patient care while meeting organizational and departmental challenges. Hospitals face unique obstacles relating to regulation and accreditation, process inefficiencies, aging or difficult-to-treat patients, allocation of resources, and patient satisfaction. This article describes the characteristics of a leader, integrative leadership in the health-care setting, and ways to engage coworkers in solving complex health-care problems.

Key Words: integrative leadership; emotional intelligence; health care

J Nucl Med Technol 2019; 47:93-96

DOI: $10.2967 /$ jnmt.118.219212

$\mathbf{H}$ ospital complexities, increased regulation, process inefficiencies, and aging or difficult-to-treat patients pose significant challenges to the health-care system (1). Delivering high-quality and highly efficient patient care and health services is further complicated by heightened patient expectations and reduced hospital resources (2). Effective patient care and treatment coordination are a requirement to ensure departmental efficiency and timeliness of service. Hospital administrators determine the organizational framework for the hospital, and the managers or leaders of departments or teams must ensure that high-quality health-care services are effectively coordinated within the given framework and that the customers' needs are met. This goal is further complicated when one realizes that the customer extends beyond the patient and must also include the patient's family, inter- and intradepartmental coworkers, ordering physicians, and radiologists, to name just a few. To meet the needs of the customer, integra-

\footnotetext{
Received Aug. 14, 2018; revision accepted Oct. 17, 2018.

For correspondence or reprints contact: Julie Bolin, Tucson Medical Center, 5301 E. Grant Rd., Tucson, AZ 85712.

E-mail: julie.bolin2@tmcaz.com

Published online Nov. 9, 2018.

COPYRIGHT (c) 2019 by the Society of Nuclear Medicine and Molecular Imaging.
}

tional leadership in the nuclear medicine department must focus on adeptness at inducing desirable responses in the immediate departmental staff and in others.

Developing and implementing leadership that facilitates cooperative, supportive, and highly functional departments is essential for maintaining not only the quality and efficiency of patient care but also healthy relationships within and between departments. In each of these departments are well-trained, highly skilled individuals who are capable of working autonomously. How, then, does a leader develop or promote an environment that not only maintains and supports autonomy but also cultivates teamwork within and among hospital departments? Integrative leadership leverages and blends the strengths and perspectives of many people within and outside a hospital department-an art that can lead to a wide range of benefits at the individual, departmental, and organizational levels (3). Variances in thinking, knowledge, experience, communication style, and critical thinking can produce a diversity of options in problem solving or coordination strategies and approaches. These characteristics of individual team members may result from different educational backgrounds, multigenerational age differences, previous life or work experience, and other factors experienced uniquely by each individual. What is important is that these unique distinctions among team members can become the secret for success if properly understood, integrated, and used in the day-to-day functioning of the nuclear medicine department. An effective leader cannot address the needs and concerns of patients, families, physicians, and other hospital employees by working in isolation or by involving only those who are like-minded individuals. Integrative leadership encourages a mutually interactive employee support network and promotes the idea that leadership is a shared responsibility.

\section{WHO IS THE LEADER? CAN IT BE ANYONE? WHAT BEHAVIORS DOES THE LEADER POSSESS?}

Leadership experts Kouzes and Posner explain that leadership is local, that "leadership can happen at anytime, 
anywhere, and in any functions" (4). Leadership within the nuclear medicine department comes in many forms. The leader may be the department manager, the charge technologist, or the staff nuclear medicine technologist. More important than the title bestowed on the leader are the characteristics of the leader. Early scholars identified intelligence and energy or charisma as defining qualities consistently found in leaders (5). Traditionally, intelligence was defined as "the ability to acquire and apply knowledge and skills" (6); however, more recent scholars have placed emphasis not only on technical skill and competency but also on emotional intelligence. Emotional intelligence, also known as emotional competency, describes characteristics about self-awareness and self-regulation such as emotional awareness, self-assessment, self-control, trustworthiness, adaptability, commitment, initiative, and drive. It also describes social or relationship characteristics such as empathy, influence, communication, conflict management, and collaboration (7). To become more self-aware, it is necessary to take an accurate appraisal of oneself, which involves honest self-reflection and assessment. Understanding what situational triggers elicit negative emotional responses such as anger or frustration will help a leader learn to pause when a negative emotion is triggered. As Marcus Aurelius once said, "You have power over your mind-not outside events. Realize this, and you will find strength" (8). That is not to imply a leader should suppress or stifle all emotions or even all negative emotions; rather, a leader must learn how to appropriately express emotions and channel that passion into more effective communication and influence. Understanding and achieving emotional finesse will prevent a negative reaction to a given situation and in turn can allow a more thoughtful action (9). Self-reflection is a great tool to evaluate personal strengths, weaknesses, and limitations. An added benefit is the increase in emotional awareness that allows a leader to recognize how emotions and reactions affect personal performance, guide decision making, and influence others.

In addition to using self-reflection or assessment to achieve a better internal understanding and self-control, it is also imperative to understand that the leader's self-reflective viewpoint may not reflect others' views of the leader. This is important because these evaluations of the leader guide the functionality of the department. Not only is it necessary to self-manage emotions and responses, but it is equally important to sense and understand the emotions or reactions of coworkers in order to build strong relationships and guide interactions to achieve the best results.

Relationship building starts with establishing strong coworker bonds. Great relationships are not established without the consent and input of all involved parties. Most colleagues or coworkers will not volunteer a forthright appraisal to another, so it may be necessary to encourage people to be candid. It is not necessary to ask every person, but trusted individuals could be solicited for a truthful appraisal of the leader's attributes or actions. Frank conver- sations are often difficult, and some people may feel extremely uncomfortable about giving constructive criticism. If coworkers are hesitant to provide feedback, send an email and request an anonymous, typed response to be returned in a sealed envelope.

Understanding how others view behavior will provide insight that is useful in establishing more appropriate relationships, better communication, and better conflict resolution. Prepare to hear less-than-positive comments. It is important to receive a truthful assessment, despite how painful it may be at the time. The opinions of coworkers are important. If coworkers are providing feedback, receive it with gratitude and engage in meaningful dialogue. Understanding others' feelings and perspectives, or actively taking an interest in their concerns, helps a leader develop empathy and promotes a better understanding of the whole situation instead of just the leader's perspective. A leader must learn to accept constructive criticism, recognize destructive patterns, and develop a strategy to manage emotions and actions or facilitate more positive interactions. This is an exercise in personal growth, which may ultimately affect professional growth and advancement. Intellectual or technical ability certainly plays a role in achieving highquality nuclear medicine examinations, but emotional intelligence is vital for relationship building, team chemistry, departmental efficiency, and collaboration (9). Eleanor Roosevelt once said, "To handle yourself, use your head; to handle others, use your heart" (10).

\section{WHAT ARE THE NEEDS OF OTHERS?}

In addition to defining the qualities of the leader, leadership theory has also focused on establishing the characteristics that followers want in leaders. Integrative leadership encourages a shared vision and an acknowledgment that achieving individual, departmental, and organizational goals requires cooperation. If a leader cannot engage the followers and inspire great group dynamics, no one will be successful. But how does a leader persuade a group to follow? Can it be as simple as placing someone in charge and expecting others to follow? That may work for a short time, but ultimately, encouraging strong leadership and genuine teamwork is the goal. Effective team leadership takes into account the needs of the followers or the team. Kouzes and Posner (9) detail the follower expectations of the leader and place significant importance on characteristics such as credibility, honesty, trustworthiness, and behavioral appropriateness and consistency. Leaders who are dedicated to understanding the needs of others and who embrace the need to develop these characteristics not only are committed to self-development but understand that meeting the needs of the team brings about departmental and organizational change.

\section{DOES EVERYONE WANT THE SAME THING?}

A multigenerational workforce may equate to different values, needs, and wants from different employees. The average nuclear medicine department may comprise 4 distinct 
generational cohorts generally grouped by birth year: silents (1925-1945), baby boomers (1946-1964), generation X (1963-1980), and millennials (1980-2000) (12). People within each generational cohort display shared personality traits as a result of experiencing significant life events and technologic advancements and enduring or witnessing events in society during the developmental stage, when they were forming opinions that influence their beliefs, values, attitudes, expectations, and behaviors (12). Other factors that influence collective personality are country of residence, economic constraints, urban or rural environment, or life-altering events such as immigration and war. Persons in the silent generation are traditional and disciplined and respect authority. Persons in the baby boomer generation tend to be competitive, to be hard-working to the point of prioritizing work over family, and to believe that people should pay their dues. Members of generation $\mathrm{X}$ are often suspicious, independent, self-reliant, and technology savvy and demand work-life balance. The millennials are technology addicted, self-indulgent, curious, collaborative, and social (12). As a leader, do not overcategorize and stereotype coworkers; rather, use the generational characteristics as a guide to better understand the wants and needs of the individuals in a group and how the characteristics of each group can pose unique challenges and opportunities for workplace harmony and collaboration.

Within the workplace, generational cohorts may vary greatly in work ethic, communication, attitudes toward authority, professional aspirations, and perception of job duties and responsibilities (12). When generational cohorts are required to work cooperatively, it is not uncommon to encounter a generational culture clash and workplace conflict. Sources of conflict arise from perceived differences in work ethic, workplace hierarchy, and technology use (12). As a leader, consider coworker needs and expectations. Better management of the expectations of the team will enable the leader to improve teamwork, increase productivity, support workplace wellness, and increase collaboration. Leaders may resolve conflict by reestablishing the priorities of the patient and the department, mentoring or coaching, and providing opportunities for each person to contribute and feel valued (12). Coworkers in the silent and baby boomer generation should be valued for their experience and organizational familiarity, whereas coworkers in generation $\mathrm{X}$ and the millennial generation should be valued for their innovation and technical acumen. A leader should cultivate or provide opportunities for the generational cohorts to learn from each other. Mix and match generations into mentoring partners and prompt them to share their skills and strengths. Mentoring provides opportunities to build mutual trust, understanding, and respect. Members of the silent and baby boomer generations can pass on their skills developed through years of experience, whereas those in generation $\mathrm{X}$ and the millennial generation can discuss creative approaches to patient care strategies and impart knowledge about innovation and technical skill. An alter- native is to partner coworkers from each generational cohort and assign them to work as a team on a specific project or task. Each person will have a distinct perspective or be able to draw from a unique skill set. Integrative leadership creates an environment that inspires trust, respect, collaboration, and innovation through the involvement of all persons, regardless of seniority.

\section{HOW SHOULD INTEGRATIVE LEADERSHIP BE USED TO ADDRESS INTER- AND INTRADEPARTMENTAL CHALLENGES?}

Working in a hospital poses significant challenges, some of which are beyond the control of the immediate nuclear medicine staff. Often, directives or changes are made at the organizational level and then filter through the levels of each department, with the director or manager initiating or implementing changes to address the challenges. When possible, work in the other direction. When problems arise, ask everyone for input or suggestions. Strongly promote participation in daily huddles, monthly departmental meetings, and interdepartmental meetings. As the people who are caring for the patients and encountering the problems, the team often develops the best solutions or can discuss as a group how directives that may affect their performance can best be managed. Encouraging participation in decision making can help the team ultimately accept, support, or promote change and enlist them as stakeholders for what is necessary for successful implementation (7). If everyone feels that their input is appreciated and valued, department morale increases because of the mutual respect and trust that is engendered between the leader and team. Collaborating with coworkers on inter- and intradepartmental changes provides them some measure of control on how to achieve the desired outcome. Not all suggestions are going to be viable or successful, but do not be afraid to try something new. If initially unsuccessful, evaluate the process, make revisions, and try again. The goal is to move in a positive direction and stimulate active participation from coworkers.

Leaders may need to develop a strategy to engage all of the team and broaden the amount of participation in group settings. Many coworkers are reluctant to provide feedback or make suggestions in a group meeting because of fear of retaliation, rejection, or embarrassment; previous bad experiences; and introversion. Some coworkers need time to think about a problem for a few days before they are ready to weigh in, whereas others are ready to offer suggestions immediately when asked. Certain coworkers have an outspoken personality that can cause them to dominate a conversation, whereas others are more reflective or quiet and prefer to speak only when directly asked. When the conversation is dominated by a couple of individuals, fewer options are presented and other coworkers are left out of the discussion altogether. To incite participation from the entire group, compose an itinerary of the problems to be discussed and email it to everyone 1 or 2 wk before the meeting. This 
will provide sufficient time for evaluation of the problem and brainstorming of ideas. As the leader, begin each brainstorming session by soliciting ideas from the group before giving an opinion. Various coworkers may automatically align with the idea of the leader instead of providing an alternative, possibly better, idea. The leader should initiate and provide structure to the meeting but allow the team to drive the conversation. Encourage everyone to weigh in, and specifically ask for input from anyone who has remained quiet. A good conversation will be inclusive and inviting to all team members. A leader who listens first and speaks later will have the benefit of learning about the team's perspectives, which provides the leader an opportunity to refine the possible solutions, combine ideas from suggestions, provide counter arguments, and ultimately accept the proposed suggestions or offer a new one. By integrating each individual's unique perspective, leaders can foster a collaborative environment where complex problems are resolved and the ultimate solution benefits the entire organization.

An integrated approach may be less daunting when solving departmental challenges than when solving interdepartmental challenges. Interdepartmental collaboration can pose additional challenges because each department involved may experience unique challenges relating to the delivery of patient care, treatment coordination, staffing, and availability of resources. When assembling a team for solving interdepartmental challenges, it is important to pay attention to the team dynamics and secure a balance in strengths and skill sets. Ensure that the composition of the team has a wide spectrum of thinking styles, traits, dispositions, and behaviors to guarantee an integrated outcome. It may be necessary to include a mentor or coach with an outside perspective on the current processes to guide the meeting and ensure that a resolution is attained. When interdepartmental conflicts or challenges arise, it is important to discuss challenges in a blame-free environment where a solution can be achieved to more effectively work together and complement one another. Inciting suggestions from the assembled group promotes active communication on all levels, a mutual understanding of expectations, sharing of information, consideration of others' ideas, exchange of resources, and a positive interdependence. Such an approach will also highlight resources that might be missing from either department so that those resources can be sought outside the team.

\section{CONCLUSION}

Leadership is an active process, and integrative leadership requires active participation from multiple leaders and followers. Solicit all coworkers for input on how to provide the best patient care experience and solve complex hospital problems. Inspire all personnel to propose revenue-generating ideas, cost-saving suggestions, and improvements for process streamlining. When there are open lines of com- munication between the leader and the team, the leader can share the requirements with the team and the team can ask questions, clarify, and make suggestions. Interactive leadership starts with building a culture that supports open dialogue, with the leader and followers feeling free to express opinions and concerns. When everyone is on the same page, both the leader and the team can better fulfill their responsibilities, provide better service to the patients, and encourage more intra- and interdepartmental cooperation. The following are summary recommendations for integrative leaders in a nuclear medicine department:

- Be the leader that others want to follow. Lead with compassion, empathy, respect, and integrity.

- Develop a leadership style to mentor, motivate, and challenge all members of the team.

- Strive to understand each coworker as individuals and to accommodate differences in values, beliefs, approaches, and performance characteristics.

- Provide opportunities for coworkers to use their unique talents individually or in a group.

- Promote group participation in problem solving. Be bold and try new ideas.

- Capitalize on the uniqueness of each coworker, using the differences between coworkers to enhance the work of the department.

\section{DISCLOSURE}

No potential conflict of interest relevant to this article was reported.

\section{REFERENCES}

1. Aij KH, Rapsaniotis S. Leadership requirements for Lean versus servant leadership in health care: a systematic review of the literature. J Healthc Leadersh. 2017;9:1-14.

2. Mannix J, Wilkes L, Daly J. Attributes of clinical leadership in contemporary nursing: an integrative review. Contemp Nurse. 2013;45:10-21.

3. Nelson G. Integrative leadership: innovating from 'The Middle Space (TMS).' The Middle Space website. http://tms.unc.edu/resources.asp. Published September 19, 2012. Accessed February 5, 2019.

4. Kouzes J, Posner B. The Leadership Challenge. San Francisco, CA: Jossey-Bass; 2010.

5. Crosby B. Feature article: theoretical foundations of integrative leadership. Integral Leadership Review website. http://integralleadershipreview.com/5000feature-article-theoretical-foundations-of-integrative-leadership/. Published August 2008. Accessed February 5, 2019.

6. Intelligence. English Oxford Living Dictionaries website. https://en.oxforddictionaries.com/definition/intelligence. Accessed February 5, 2019.

7. Goleman D. Working with Emotional Intelligence. Kennett Square, PA: Soundview Executive Book Summaries; 2011.

8. Stoicism: meditations and the wisdom of Marcus Aurelius. Academy of Ideas website. https://academyofideas.com/2016/05/stoicism-meditations-the-wisdomof-marcus-aurelius/. Published May 15, 2016. Accessed February 5, 2019.

9. Kouzes J, Posner B. The Truth About Leadership. Kennett Square, PA: Soundview Executive Book Summaries; 2010.

10. Perlman A, Horrigan B, Goldblatt E, Maizes V, Kligler B. The pebble in the pond: how integrative leadership can bring about transformation. Explore (NY). 2014;10(suppl):S1-S14.

11. Eleanor Roosevelt quotes. Goodreads.com website. https://www.goodreads.com/ author/quotes/44566.Eleanor_Roosevelt. Accessed February 5, 2019.

12. Kramer LW. Generational diversity. Dimens Crit Care Nurs. 2010;29:125-128. 